\title{
Cognitive decline in patients with Parkinson's disease
}

\author{
Denisa Floriana Vasilica Pirscoveanu', Valerica Tudorica', Cornelia Zaharia², \\ Carmen Valeria Albu', Simona Bondari', Puiu Olivian Stovicek ${ }^{3}$, Mircea Pirscoveanu' ${ }^{1}$ \\ ${ }^{1}$ University of Medicine and Pharmacy, Craiova, Romania \\ ${ }^{2}$ Department of Neurology, Hospital of Neuropsychiatry, Craiova, Romania \\ 3"Titu Maiorescu" University, Targu Jiu, Romania
}

\begin{abstract}
The goal of our study was to assess the cognitive state in patients with Parkinson's disease (PD). We studied 62 patients (30 men and 32 women, mean age $71.1 \pm 4.5$ years and mean educational level $11.5 \pm 1$ years). They were admitted to the Clinic of Neurology from Craiova between January 2015 - January 2016 for Parkinson's disease. All the patients met the diagnostic criteria for Parkinson's disease. In this study we included only patients in stage I and II on Hoehn and Yahr scale. 35 patients were in stage I and 27 patients in stage II. The patients were treated with levo-dopa monotherapy or dopaminergic agonists monotherapy. We have also included in our study a control group composed of 70 control subjects with the same range of educational level and age. To assess the cognitive state we tested the patients using Cambridge Cognitive Examination (CAMCOG) and the revised version of the Addenbro-oke's Cognitive Examination (ACE-R) at baseline, after 6 months and one year later. For the statistical analysis, we used Student test ( $p<0.05$ statistically considerable). At baseline the patient group showed a mean CAMCOG score 92.5 and a mean ACE-R score 89.6. The control subjects showed a mean CAMCOG score 94.3 and a mean ACE-R score 90.2. One year later the patient group showed a mean CAMCOG score 83.5 and 84.3 mean ACE-R score. The control group showed a mean CAMCOG score 90.2 and mean ACE-R score 88.3. The patients with PD showed a greater cognitive impairment than the control subjects. We observed that the patients in stage II Hoehn and Yahr had a greater cognitive impairment than patients in stage I. We have also seen in patient group a cognitive decline across every ACE-R and CAMCOG cognitive domain.
\end{abstract}

Keywords: cognitive impairment, Parkinson's disease, CAMCOG, ACE-R

\section{INTRODUCTION}

Parkinson's disease (PD) is a neurodegenerative disorders of unknown etiology, characterized by tremor, rigidity, bradykinesia and impairment of balance that are usually of an asymmetric course (1). The neuropathology of PD affects several structures that are implicated in movement control. Non-motor features of PD include not only cognitive impairment and dementia, but also mood disorders, psychosis, sleep disturbances and autonomic dysfunction. These non-motor features have been associated with increased disability and reduced quality of life (2).

Studies of Parkinson's disease patients followed over many years reveal that non-motor symptoms become even more important as Parkinson's disease advances (3). Increased recognition and improved treatments for these non-motor symptoms are greatly needed.

PD is predominantly characterised as a movement disorder, which affects about $1 \%$ of the population over age 60 (4). Over the past years there has been an increasing awareness that the clinical spectrum of PD is much broader, also encompassing many non-motor domains (4). Especially neuropsychiatric symptoms such as depression, psychosis, anxiety and cognitive impairments may contribute to reduced quality of life in PD patients (5).

Cognitive symptoms in Parkinson's disease are common, though not every person experiences 
them. In some people with PD, the cognitive changes are mild. In others, however, cognitive deficits may become more severe and impact daily functioning (6). Similar to slowness of movement (or bradykinesia), people with Parkinson's disease often report slower thinking and information processing (termed "bradyphrenia") (7).

Dementia is common and affects approximately $40 \%$ of PD patients during the course of the disease (8). The reported prevalence of dementia in PD varies greatly $(2-81 \%)$ between studies (9). Dementia may be difficult to recognize in PD. Dementia in Parkinson's disease typically develops many years after the initial onset of Parkinson's disease and is more common with advanced disease (10). When dementia develops before or at the same time as the Parkinson's disease motor symptoms, patients are often given the diagnosis of dementia with Lewy bodies (11).

Motor slowing, anticholinergic medications and depression may further impair cognitive function and also confound testing. These deficits, although clinically significant for the patient, are generally considered to be too mild to warrant a diagnosis of dementia (12).

The exact cause of cognition impairment in PD are not fully known but are likely due to a combination of chemical and structural changes (13). In addition to dopamine, Parkinson's affects acetylcholine, norepinephrine and serotonin, that support cognitive and mood function (13).

The dementia associated with PD is characterized by a dysexecutive syndrome affecting mainly executive and visuospatial functions while memory is relatively preserved (3). Cognitive deficits in PD have been seen as an executive dysfunction secondary to frontostriatal system impairment (14). Evaluation of memory in PD patients has largely focused on explicit memory and implicit memory. A number of studies demonstrate clearly that both verbal and nonverbal explicit memory can be disrupted in PD patients without dementia $(5,6,8,15)$. Story recall is considered to be verbal contextual declarative memory because it provides a framework for the information. Impairments in both immediate and delayed story recall have been reported in patients with PD $(16,17)$.

A lot of aspects of cognitive decline in PD are still unclear because of the use of different and of- ten invalid measurement instruments (18). Several longitudinal studies have shown that cognitive decline is a harbinger of dementia in $\mathrm{PD}$, although the course is variable and stabilization of cognition is not incommon (19). Cognitive impairment in PD is associated with nursing home placement, mortality and increased caregiver burden (20-22).

There are several ways to assess cognition in the clinical or in the research setting. Reports from the patient and the patient's caregiver are important sources of information. The physician may ask questions about cognitive function, whether the cognitive problems represent a change from prior functioning, and how it impacts activities of daily living or work. The cognitive evaluation include multiple tests to assess different cognitive domains. Some of the tests require oral answers, while others use a pencil and paper. This evaluation may range from about 45 minutes to several hours.

\section{MATERIAL AND METHODS}

We studied two groups in this study. Patients group consisted of 62 patients (30 men and 32 women, mean age $71.1 \pm 4.5$ years and mean education level $11.5 \pm 1$ years) admitted to the Clinic of Neurology from Craiova between January 2015 and January 2016 for PD. All the patients met the diagnostic criteria for Parkinson's disease. Thirty-five patients were in stage I and 27 patients in stage II Hoehn and Yahr Scale. The patients were treated with levo-dopa monotherapy (42 of the patients) or dopaminergic agonists monotherapy (20 of the patients). The second groupe was a control group consisted of 70 subjects (40 men and 30 women), without PD, mean age $71 \pm 4.1$ years and mean educational level $11.7 \pm 1.5$ years. Upon giving an informed consent, both groups were tested using CAMCOG and ACE-R.

CAMCOG forms a part of a standardized psychiatric assessment schedule, CAMDEX (Cambridge Examination for Mental Disorders of the Elderly), devised by Roth and colleagues and published by Cambridge University Press. CAMCOG assess a wide range of cognitive domains such as attention, memory, abstraction, language, praxis,orientation and perception. The maximum overall score is 105 . A cut-off of 80 was found to discriminate between demented and normal subjects (23). 
ACE-R was developed in an attempt to provide a test with greater sensitivity to early cognitive decline than the MMSE. ACE-R is a brief cognitive test that assesses five cognitive domains: attention, orientation, memory, verbal fluency, language and visuospatial abilities. Total score is 100 , higher score indicates better cognitive functioning (24).

Our evaluations were made in the beginning of the study (baseline) than after 6 months, respectively 12 months. We compared the results obtained in the patients group with those from control group and we have also followed-up which are the most impaired cognitive functions. Then, we estimated the cognitive performances related to the stage of the disease and also related to the therapy. The results were analysed by Student Test $(p<0.05$ statistically considerable).

\section{RESULTS}

We represented our demographic findings in Table 1 . No significance between group differences were observed in demographic variables, except for education (it was lower for the patients with cognitive impairment).

At baseline, mean CAMCOG 92.5 score in the patient group was points and a mean ACE-R score was 89.6 points. The control group showed a mean CAMCOG 94.3 score points and a mean ACE-R score of 90.2 points. After 6 months, the patients with PD showed a mean CAMCOG score of 88.4 points and a mean ACE-R score of 86.1 points. The control group showed a mean CAMCOG score of 92.2 points and a mean ACE-R score of 89.1 points. One year later the patients group showed a mean CAMCOG score of 83.5 points and a mean ACE-R score of 84.3 points. The control subjects showed a mean CAMCOG score of 90.2 points and a mean ACE-R score 88.3 points (Fig. 1, 2).

The assessment of the cognitive preformances related to the stage of the disease showed the next CAMCOG scores: in the stage I group patients: mean score at baseline was 92.8 points, after 6 months 89.7 points and one year later 84.7 points. In stage II group patients the mean CAMCOG score at baseline was 92.1 points, after 6 months 87.3 points and after 1 year 81.3 points. The assessment using ACE-R revealed in stage I group patients a mean score at baseline of 89.5 points, after 6 months 87.5 points and one year later 84.6 points. In stage II group patients the mean ACE-R score was 89.3 at baseline, 86.2 points after 6 months and 83.2 points after one year (Fig. 3,4 ). The statistical analyse regarding the most affected cognitive ACER and CAMCOG domains is represented on Fig. 5.

$62 \%$ of the patients trated with levodopa monotherapy showed a cognitive impairment while 59\% of the patients treated with dopamine agonists.

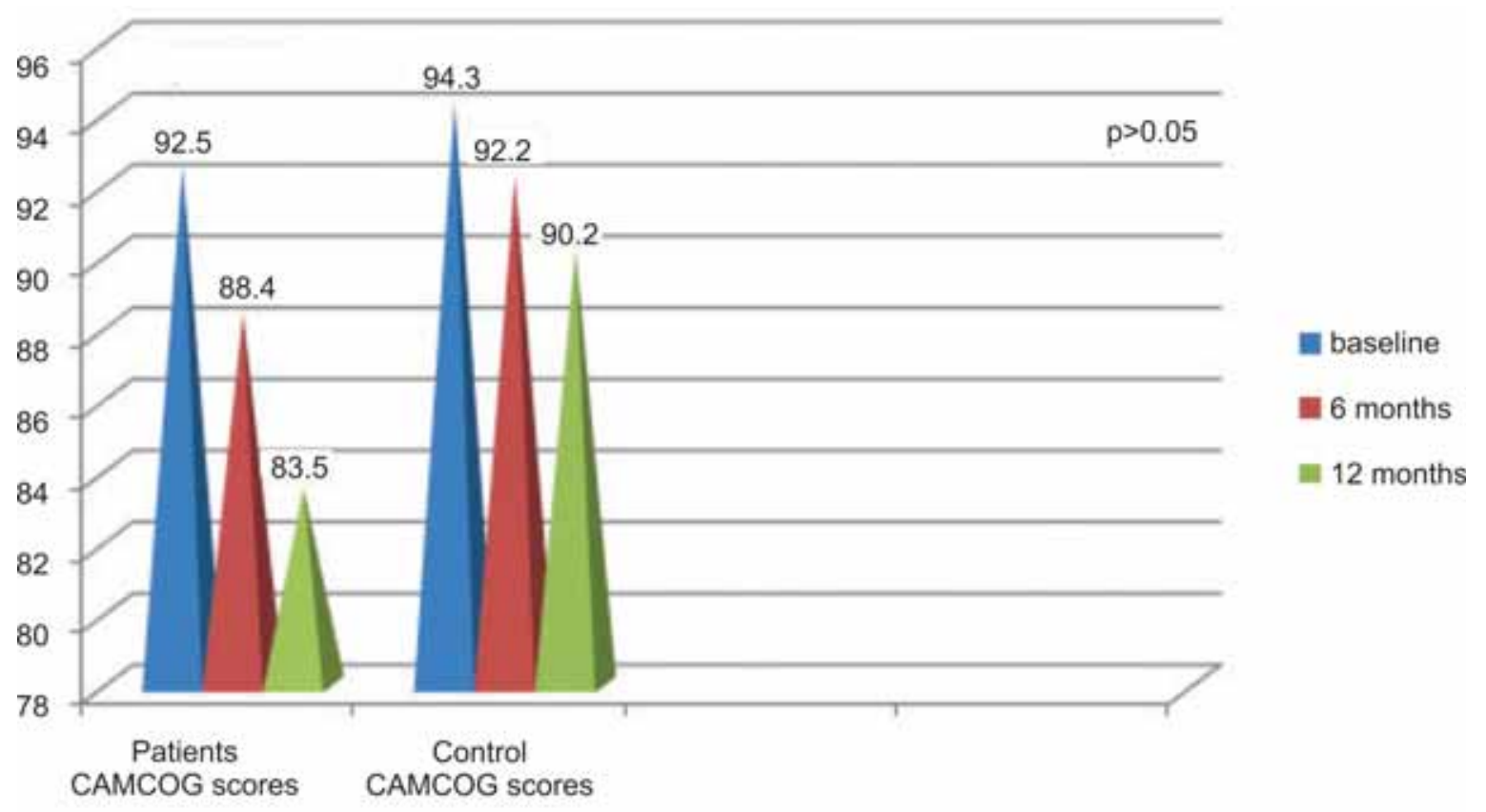

FIGURE 1. CAMCOG scores in dynamics in patients group and control group 


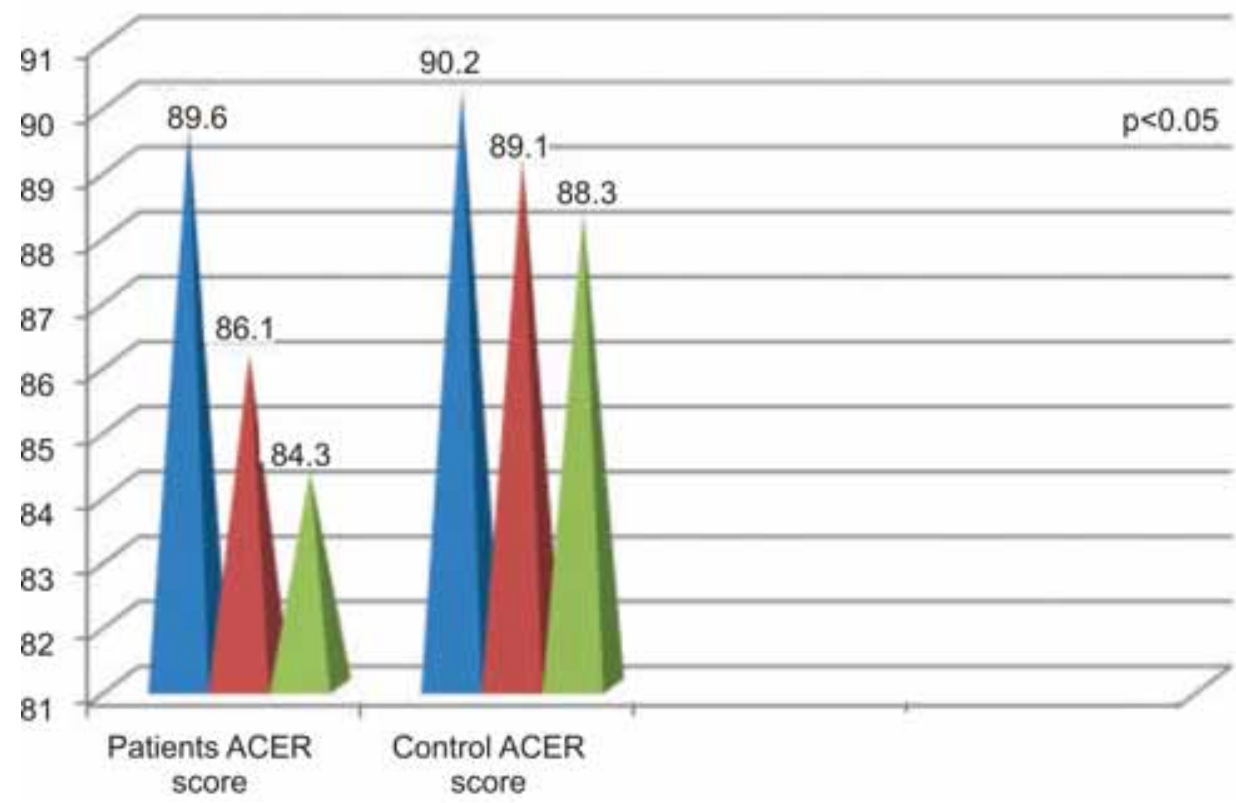

baseline

6 months

12 months

FIGURE 2. ACER scores in dynamics in patients group and control group

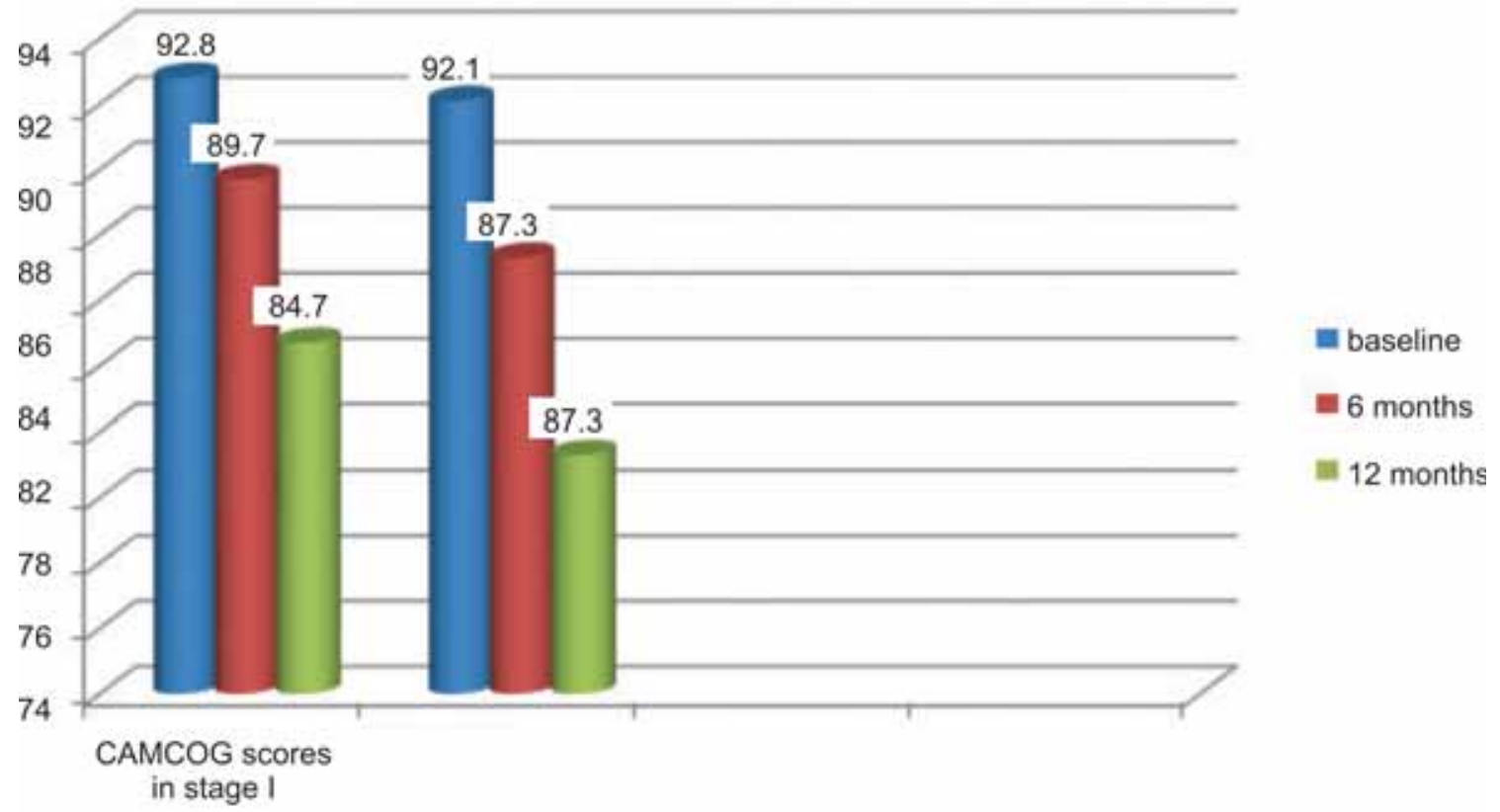

FIGURE 3. Cognitive assessment using CAMCOG in group patients depending on stage of Parkinson's disease

TABLE 1. The demographic findings in PD patients group and control group

\begin{tabular}{|l|c|c|c|c|}
\hline & $\begin{array}{c}\text { Cogni ve } \\
\text { impairment }\end{array}$ & $\begin{array}{c}\text { Non-cogni ve } \\
\text { impairment }\end{array}$ & $\begin{array}{c}\text { Cogni ve } \\
\text { impairment }\end{array}$ & $\begin{array}{c}\text { Non-cogni ve } \\
\text { impairment }\end{array}$ \\
\hline Age (years) & $72 \pm 2.1$ & $71 \pm 3.1$ & $71 \pm 3$ & $70 \pm 3.9$ \\
\hline Men (number) & 13 & 10 & 21 & 19 \\
\hline Women (number) & 19 & 16 & 12 & 10 \\
\hline Educa onal level (years) & $9.7 \pm 1.2$ & $11.8 \pm 1.1$ & $10 \pm 1.1$ & $12 \pm 1$ \\
\hline
\end{tabular}




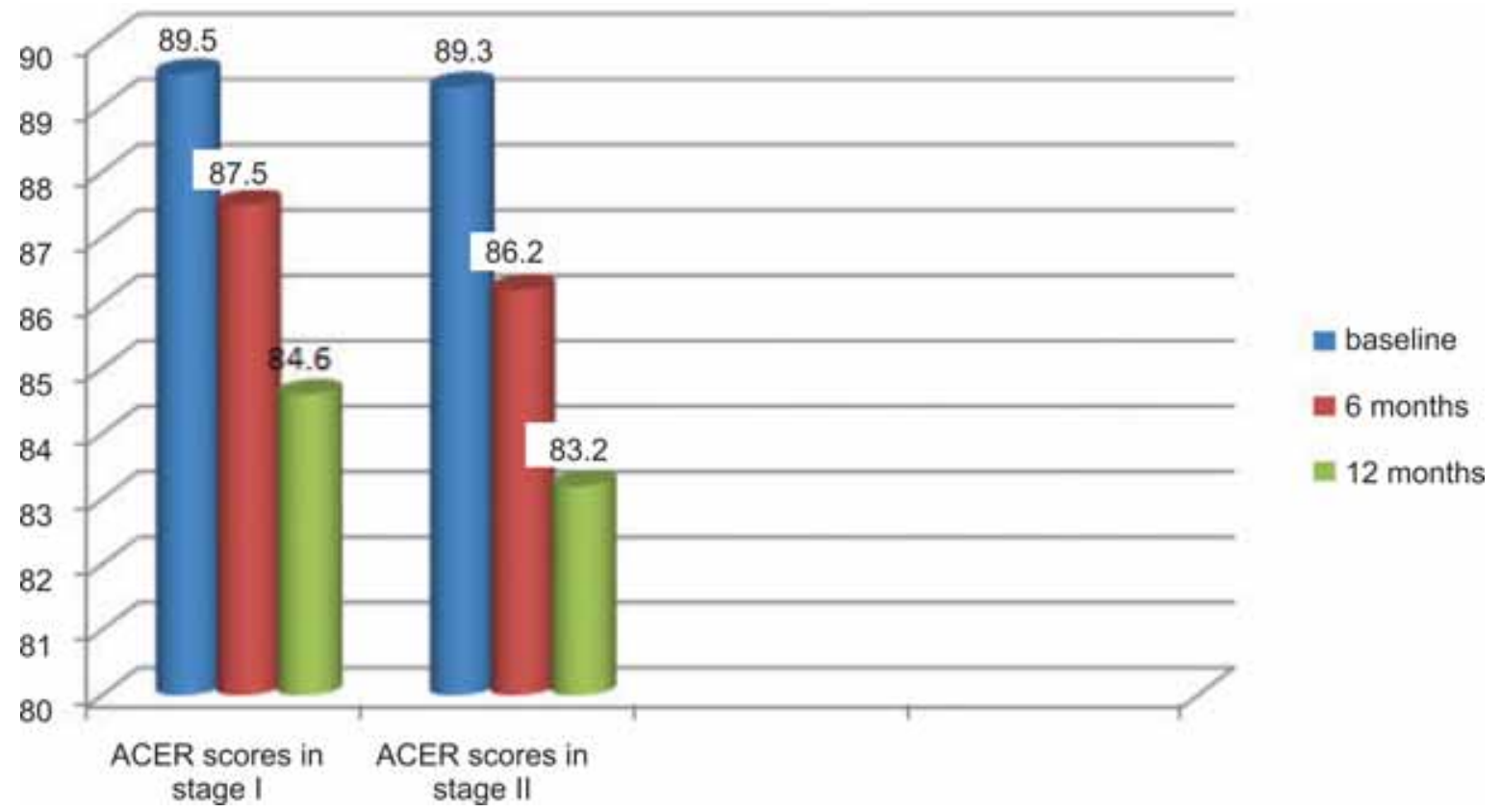

FIGURE 4. Cognitive assessment using ACER in group patients depending on stage of Parkinson's disease

\section{Cognitive domains affected}

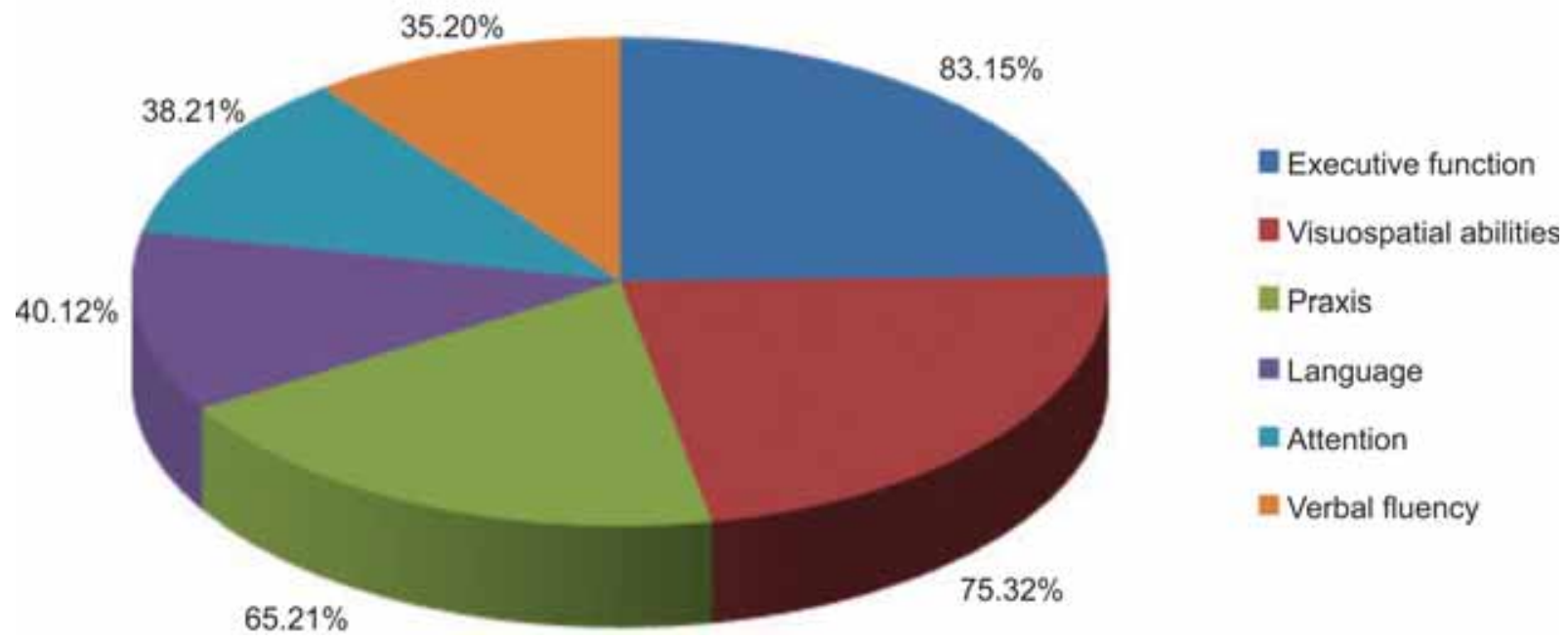

FIGURE 5. Cognitive domains affected in patients with Parkinson's Disease

\section{DISCUSSIONS}

Cognitive impairment is an increasingly recognized non-motor complication of Parkinson's disease with significant clinical impact. It has an important consequences for patient management.

Cognitive decline in patients with Parkinson's disease is associated with significant disability for patients and burden for caregivers. The exact causes of cognitive impairment or dementia in Parkinson's disease are not fully understood. There may be changes in the neurochemical signals that the brain uses to pass along information to different regions of the brain. Similar to motor symptoms, the characteristics of cognitive impairment in Parkinson's disease can be quite variable, both in terms of what cognitive domains are impaired and the timing of onset and rate of progression.

Cognitive impairment, with or without dementia, is a problem from the earliest stages of Parkinson's disease and contributes significantly to the morbidity and mortality of the disease (25).

Although the cognitive deficits of idiopathic Parkinson's disease are relatively known, their neu- 
ropsychological and neurobiological basis are still discussed. Deficits in cholinergic, noradrenergic and dopaminergic mechanism have been proposed as the basis of cognitive impairment of Parkinson's disease (26).

Our study showed a decrease of the cognitive performances in dynamic during the year study both in group of Parkinson's disease patients and control group. As we said, using CAMCOG and ACE-R for the cognitive assessment, we observed that group patients with Parkinson's disease showed a higher cognitive impairment than the control group after both 6 months, but it is was not significantly statistical $(p>0.05)$. At the end of our year study, we noticed an increased cognitive impairment in comparison with baseline, statisticaly significant $(\mathrm{p}<0.05)$. Our results are in concordance with other studies that observed a cognitive impairment increased in dynamics in patients with Parkinson's disease $(18,25,27)$. Generally it is assumed that cognitive impairment may develop early in the disease, but clinical symptoms of dementia appear only on late course of the disease $(25,27)$.

We observed in our study a higher cognitive impairment at patients in stage II Hoehn and Yahr than those in stage I. Patients in stage I Hoehn and Yahr presented their cognitive decline increased during the year study, but insignificantly statistical. At the other hand, the patients in stage II Hoehn and Yahr showed a cognitive impairment statistically significant after one year in comparison with baseline. We also found this result in other studies, that concluded that risk of developing dementia increases with disease progression $(17,28,29)$.

In this study we also focused to observe the changes in different cognitive domains in patients with Parkinson's disease. We found that executive functions were the most affected cognitive domain in our patients (83.15\% of our patients). Executive function includes the ability to plan, organize, initiate and regulate goal directed behavior. It is involved the prefrontal cortex of the brain and the dopamine system, which are affected in Parkinson's disease and it is one of the most common cognitive changes reported in these patients. Treatment with dopaminergic medication has variable effects on executive deficits, improving some, leaving some unchanged and worsening others (30). The exact pattern of executive impairment is un- clear. There is an ongoing discussion surrounding the definition of executive function (31).

After executive dysfunction in our patients, we found a great impairment of visuospatial abilities in our patients $(75.32 \%)$. These abilities tell us where things are around us in space, give us a spatial map of our environment and involve our sense of direction. Visuospatial functions allow us to estimate distance and depth perception, use mental imagery, copy drawings, or construct objects or shapes. This includes pattern recognition (facial recognition), constructional ability (figure drawing), color recognition (color naming) and spatial analysis (5). The posterior cortical areas have been associated with deficits in visual processing including the occipital, parietal and temporal lobes. Neuroimaging suggests that visuospatial impairment in Parkinson's disease without dementia is associated with posterior cortical dysfunction $(5,32)$. It seems that decreases in spatial orientation functioning in Parkinson's disease may reflect the speed of progression of this disease (33). In $65.21 \%$ of the patients we found an altered praxis. We correlated the impairment of praxis with stage of the disease and found that praxis was more affected in stage II Hoehn and Yahr in comparison with stage I.

While there is a general acknowledgement that persons with Parkinson's disease may experience declines in executive functions, praxis, visuospatial abilities, there is less agreement concerning language impairments $(5,34)$.

$40.12 \%$ of the patients included in our study presented an impairment of the language. We detected language impairment even in patients on stage I Hoehn and Yahr (25\% of them showed language impairment). Language abilities include naming objects, generating words, comprehension, and verbal concepts. The most common language problem in our patients was finding the "right" words. Pacients with Parkinson's disease tend to speak less overall (in addition to softer voice) and use simpler speech. This can be an area of frustration for the patient and caregiver.

It is well known that attention is an other cognitive domain affected in Parkinson's disease. We also found in our research that $38.21 \%$ of the patients included in this study had an impairment of their attention.

Attention is the process of filtering information related to internal and external stimuli. In general, 
this cognitive process can be treated as two separate processes, one that is relatively simple, bottom-up (data-driven) and automatic and a second that is relatively complex, top-down and controlled. There is some disagreement on whether Parkinson's disease patients without dementia are at risk for deficits in simple attention (5).

Memory functions seem to be relatively preserved in patients with PD and cognitive decline $(8,26)$. We found in our study a small percentage of patients affected in this cognitive domain $(20.1 \%$ of our patients). Memory is not a unitary construct; rather there are multiple memory systems subserved by multiple brain structures: emotional memory is dependent on the amygdala and hippocampus, while implicit memory is subserved by the basal ganglia, motor cortex and cerebellum (5).

When we studied the relationship between the therapy of Parkinson's disease and the range of the cognitve decline we did not observe a considerable difference between patients treated with levodopa therapy and patients treated with dopamine ago- nists therapy. They showed approximately the same range of cognitive decline during the year of study. There are variable effects of dopaminergic medications on Parkinson's disease cognition. Some studies report improved alertness, working memory and planning abilities. Other studies find no effect of dopaminergic medications on Parkinson's disease cognition, and some report increased cognitive symptoms (35-37).

\section{CONCLUSIONS}

Cognition is an important domain of the clinical spectrum of Parkinson's disease and we emphasize the importance of neuropsychological assessment of these patients, significant in that early recognition of cognitive decline could offer opportunities for novel therapeutic intervention.

In our opinion, the pattern of early cognitive impairment in Parkinson's disease may provide clues to the underlying pathologic processes leading to cognitive decline.

Conflict of interest: none declared Financial support: none declared

\section{REFERENCES}

1. Aarsland D., Zaccai J., Brayne C. A systematic review of prevalence studies of dementia in Parkinson's disease. Mov Disord. 2005; 20(10):1255-1263.

2. Aarsland D., Bronnick K., Larsen J.P., Tysnes O.B., Alves G. Cognitive impairment in incident, untreated Parkinson disease: the Norwegian ParkWest study. Neurology. 2009; 72(13):1121-1126

3. Galvin J.E. Cognitive change in Parkinson's disease. Alzheimer Dis Assoc Disord. 2006; 20(4):302-310.

4. Chandhiri K.R., Healy D.G., Schapira A.H. Non motor symptoms of Parkinson Disease: diagnosis and management. Lancet. Neurol 2006; 5: 235-245

5. Stennis G.W., Leverenz J.B. Profile of cognitive impairment in Parkinson Disease. Brain Pathol 2010; 20(3): 640-645

6. Goldman W.P., Baty J.D., Buckles V.D., Sahrmann S., Morris J.C. Cognitive and motor functioning in Parkinson's disease: subjects with and without questionable dementia. Arch Neurol. 1998; 55(5):674-680.

7. Janvin C.C., Larsen J.P., Aarsland D., Hugdahl K. Subtypes of mild cognitive impairment in Parkinson's disease: progression to dementia. Mov Disord. 2006; 21(9):1343-1349.

8. Dodel R. Dementia in Parkinson Disease. Orphanet Encyclopedia 2004: 1-5

9. Emre M. Dementia associated with Parkinson Disease. Lancet Neurol 2003; 2: 229-237.

10. Merims D., Freedman M. Cognitive and behavioural impairment in Parkinson's disease. Int Rev Psychiatry. 2008; 20(4):364-373.

11. Troster A.I. Neuropsychological characteristics of dementia with Lewy bodies and Parkinson's disease with dementia: differentiation, early detection, and implications for "mild cognitive impairment" and biomarkers. Neuropsychol Rev. 2008; 18(1):103-119.
12. Williams-Gray C.H., Foltynie T., Lewis S.J., Barker R.A. Cognitive deficits and psychosis in Parkinson's disease: a review of pathophysiology and therapeutic options. CNS Drugs. 2006; 20(6):477-505.

13. Milner B., Squire L.R., Kandel E.R. Cognitive neuroscience and the study of memory. Neuron. 1998; 20(3):445-468

14. Aarsland D., Perry R., Brown A., Larsen J.P., Ballard C. Neuropathology of dementia in Parkinson's disease: A prospective, community-based study. Ann Neurol. 2005; 58(5):773-776.

15. Costa A., Peppe A., Caltagirone C., Carlesimo G.A. Prospective memory impairment in individuals with Parkinson's disease. Neuropsychology. 2008; 22:283-292 Tinklenberg J.R., Pfefferbaum A. Extent, pattern, and correlates of remote memory impairment in Alzheimer's disease and Parkinson's disease. Neuropsychology. 2000; 14(2):265-276

17. Muslimovic D., Post B., Speelman J.D., Schmand B., de Haan R.J. Determinants of disability and quality of life in mild to moderate Parkinson's disease. Neurology. 2008; 70(23):2241-2247

18. Verbaan D., Marinus J., Visser M. et al. Cognitive impairment in Parkinson's Disease. J Neurol Neurosurg Psychiatry 2007; 28:1182-1187

19. Aarsland D., Creese B., Politis M., Chandhuri K.R., Ffytche D.H., Weintraub D., Ballard C. Cognitive decline in Parkinson's Disease. Nat Rev Neurol 2017; 13(4) : 217-231

20. Aarsland D., Larsen J.P., Karlsen K., Lim N.G., Tandberg E. Mental symptoms in Parkinson Disease are important contributors to caregiver distress. Int J Geriatr. Psychiatry 1999; 14(10): 866-874

21. Aarsland D., Larsen J.P., Tandbery E., Laake K. Predictors of nursing home placement in Parkinson's Disease: a population based, prospective study. J Am Geriatr Soc 2000; 48(8): 938-942
16. Fama R., Sullivan E.V., Shear P.K., Stein M., Yesavage J.A., 
22. Levy G., Tang M.X., Louis E.D., Cote L.J., Alfaro B., Mejia H., Stern Y., Marden K. The association of incident dementia with mortality in PD. Neurology 2002; 59(11): 1708-1713

23. Roth M., Tym E., Mountjoy C., Huppert F.A., Hendrie H., Verma S. et al. (1986) CAMDEX. A standardized instrument for the diagnosis of mental disorder in the elderly with special reference to the early detection of dementia. Br J Psychiatry 149: 698-709

24. Mioshi E., Dawson K., Mitchell J., Arnold R., Hodges J.R. (2006) The Addenbrooke's Cognitive Examination Revised (ACE-R): a brief cognitive test battery for dementia screening. Int $J$ Geriatr Psychiatry 21: 1078-1085

25. Aarsland D., Andersen K., Larsen J.P., Lolk A., Kragh-Sorensen P. Prevalence and characteristics of dementia in Parkinson disease: an 8-year prospective study. Arch Neurol. 2003; 60(3):387-392.

26. Pillon B., Czernecki V., Dubois B. Dopamine and cognitive function. Curr Opin Neurol 2003;16 Suppl 2: S17-22

27. Fuchs G.A., Gemende I., Herting B. et al. Dementia in idiopathic Parkinson syndrome. J Neurol 2004; 251(Suppl 6)VI/ 28-32.

28. Braak H., Rub U., Steur E.N.H., Tredici Del K., Vos R. Cognitive status correlates with neuropathologic stage in Parkinson disease. Neurology 2005; 64(3): 1404-1410

29. Braak H., Rub U., Tredici Del K. Cognitive decline correlates with neuropathological stage in Parkinson disease. Journal of the Neurological Sciences 2006; 248(1-2) :255-258

30. Dirnberger G., Jahanshahi M. Executive dysfunction in Parkinson disease: a review. J. Neuropsychol 2013; 7(2): 193-224
31. Kudlicka A., Clare L., Hindle J. Executive functions in Parkinson disease: Systematic review and meta-analysis. Movement Disorders 2011; 26(13): 2305-2315

32. Abe Y., Kachi T., Kato T., Arahata Y., Yamada T., Washimi Y., Iwai K., Ito K., Yanagisawa N., Sobue G. Occipital hypoperfusion in Parkinson's disease without dementia: correlation to impaired cortical visual processing. Journal of Neurology, Neurosurgery, and Psychiatry. 2003; 74(4):419-422.

33. Raskin S.A., Borod J.C., Wasserstein J., Bodis-Wollner I., Coscia L., Yahr M.D. Visuospatial orientation in Parkinson disease. Int $J$ Neurosci 1990; 51(1-2): 9-18

34. Williams-Gray C.H., Foltynie T., Brayne C.E., Robbins T.W., Barker R.A. Evolution of cognitive dysfunction in an incident Parkinson's disease cohort. Brain. 2007;130 (7):1787-1798.

35. Roshan C. Dopaminergic modulation of cognitive function- implications for L-Dopa treatment in Parkinson disease. Neuroscience and Biobehavioral Reviews 2006; 30(1) : 1-23

36. Cools R. Dopaminergic control of the striatum for high-level cognition. Current Opinion in Neurobiology. 2011;21(3):1-6.

37. Costa A., Peppe A., Dell'Agnello G., Caltagirone C., Carlesimo G.A. Dopamine and cognitive functioning in de novo subjects with Parkinson's disease: effects of pramipexole and pergolide on working memory. Neuropsychologia. 2009; 47(5):1374-1381 